\title{
Editorial Note: ITMN Special Issue
}

One of the aims of this journal is to provide a platform for the publication of work by young and new researchers, who may be at the beginning of their research careers, or who have carried out applied research as part of a graduate programme aiming to bridge a gap between academia and the professional world.

As a step towards achieving this aim, this special issue specifically set out to showcase some of the work that has recently emerged from masters' level programmes at universities which are linked together through the International Tourism Masters Network (ITMN).

ITMN is a network of tourism master awarding universities and industry partners, whose main objective is to foster international collaboration and optimise the benefits of exchange - whether of information, knowledge, ideas or people - among students, graduates, faculty staff and tourism professionals (www.itmn-tourismmasters.org).

The call for papers initially attracted interest from currently enrolled students and alumni of several of the ITMN partnership universities. The complete and rigorous process of double-blind peer review which all submissions went through culminated in the 7 articles which make up this special issue: 5 full research papers and 2 critical literature reviews.

The first two papers take us to Indonesia, where the authors report on research carried out during field trips as part of the Tourism Destination Management Masters programme at Breda University of Applied Sciences in the Netherlands. First off, Ellis Middelkamp invites us to better understand ethnic tourism experiences in Sade Rembitan, one of the few remaining villages on the island of Lombok that is still inhabited by its original people, and which is increasingly being promoted as a tourist attraction. The study finds some interesting differences between the experiences of domestic and international tourists to the village, and ends with a number of recommendations on how to enhance these experiences.

In the second paper, Kludzeweit, Kamargiannis, Tirta and Middelkamp take us to the newly fashionable area of Canggu in Bali, where rapid tourism development is presenting challenges to the local community. Their research reports on the present situation and provides a view of the "preferable future" of the area, along with some reflective recommendations on how micro- and small enterprises might strengthen their strategic positionings whilst aiming towards this desirable future.

The third paper, authored by Minéa Funk and her supervisor Albina Pashkevich, from Dalarna University in Sweden, takes us into the heart of the Bergslagen area of central Sweden, an area which has a long history of mining and nowadays has several industrial heritage sites. Through the lens of post-feminism, this study explores the representations found in the destination marketing materials and comes to the conclusion that they continue to rely on 
patriarchal narratives of the region and its heritage, whilst excluding the role of women and 'other' alternative narratives.

Also from Dalarna University, Simona Tichá and her supervisor loanna Farsari have contributed a study based in the tourism destination of Bohemian Switzerland, in the Czech Republic. The study shows how an analysis of interview data guided by the synergy view of social capital, incorporating different destination stakeholders, can reveal which elements are most important in facilitating collaboration and strengthening relationships among these stakeholders.

The next paper comes from the Universidad Central "Marta Abreu" de Las Villas in Cuba. Giselle Rodríguez Jiménez, along with her supervisors Alicia de la Concepción Alfonso Serafín and Carlos Cristóbal Martínez Martínez, set out to draw up best practice procedures for the structured design of a regional tourism destination management strategy for Villa Clara, in Cuba. In order to achieve this, the authors argue not only for the need to take the specific contextual factors of the Cuban tourism sector and its tourism destinations into account, but also for the need to base senior management strategic actions on scientifically based studies.

The two final papers provide comprehensive literature reviews on two very different subjects. In the first paper, Sarah Radzanowski and her supervisor Lauren Uğur, from Heilbronn University of Applied Sciences in Germany, tackle the concept of sustainability in tourism development by exploring the ways that resilience has been conceptualised within the context of complex adaptive systems. They ask to what extent resilience can be applied as a development strategy for tourism destinations and conclude that although further research is needed to develop implementable frameworks, it seems clear that resilience must be fostered first and foremost at community level.

In the final paper of the issue, Anderson Oliveira and his supervisors Ana Renda and Marisol Correia, from the School of Management, Hospitality and Tourism of the University of Algarve in Portugal, explore the question of how online reviews can be employed to improve hotel management practices. This review of the literature uncovers a range of approaches to the use of online reviews as a support instrument for hospitality business development, thus showing the potential for the professional applications of this type of research.

We would like to thank all the authors for their commitment and contribution to this exciting special issue, which we hope will inspire other Tourism Masters students and alumni to consider publishing their work in scientific journals.

The Editors,

Rita Baleiro \& Kate Torkington 